\title{
Research priorities in observing and modeling urban weather and climate
}

\section{Article}

Published Version

Chen, F., Bornstein, R., Grimmond, C. S. B., Li, J., Liang, X., Martilli, A., Miao, S., Voogt, J. and Wang, Y. (2012) Research priorities in observing and modeling urban weather and climate. Bulletin of the American Meteorological Society, 93 (11). pp. 1725-1728. ISSN 1520-0477 doi: https://doi.org/10.1175/BAMS-D-11-00217.1 Available at https://centaur.reading.ac.uk/34418/

It is advisable to refer to the publisher's version if you intend to cite from the work. See Guidance on citing.

To link to this article DOI: http://dx.doi.org/10.1175/BAMS-D-11-00217.1

Publisher: American Meterological Society

All outputs in CentAUR are protected by Intellectual Property Rights law, including copyright law. Copyright and IPR is retained by the creators or other copyright holders. Terms and conditions for use of this material are defined in the End User Agreement.

\section{www.reading.ac.uk/centaur}

\section{CentAUR}


Central Archive at the University of Reading

Reading's research outputs online 


\section{RESEARCH PRIORITIES IN OBSERVING AND MODELING URBAN WEATHER AND CLIMATE}

by Fei Chen, Robert Bornstein, Sue Grimmond, Ju Li, Xudong Liang, alberto Martilli, Shiguang Miao, James Voogt, and Yingchun Wang

I n 2007, the world reached the unprecedented milestone of half of its people living in cities, and that proportion is projected to be $60 \%$ in 2030 . The combined effect of global climate change and rapid urban growth, accompanied by economic and industrial development, will likely make city residents more vulnerable to a number of urban environmental problems, including extreme weather and climate conditions, sea-level rise, poor public health and air quality, atmospheric transport of accidental or intentional releases of toxic material, and limited water resources.

AFFILIATIONS: CHEN-National Center for Atmospheric Research,* Boulder, Colorado; BORNSTEIN-Department of Meteorology, San Jose State University, San Jose, California; GrImMOND-Environmental Monitoring and Modelling, Geography, King's College London, London, United Kingdom; LI, LIANG, MIAO, AND WANG-Institute of Urban Meteorology, China Meteorological Administration, Beijing, China; MARTILLICenter for Research on Energy, Environment and Technology, Madrid, Spain; VoogT-Department of Geography, University of Western Ontario, London, Ontario, Canada

*The National Center for Atmospheric Research is sponsored by the National Science Foundation CORRESPONDING AUTHOR: Fei Chen, NCAR/RAL, P.O. Box 3000, Boulder, CO 80307-3000

E-mail: feichen@ucar.edu

DOI:10.II75/BAMS-D-II-00217.I

In final form 7 February 2012

()2012 American Meteorological Society

\section{INTERNATIONAL WORKSHOP ON URBAN WEATHER AND CLIMATE: OBSERVATION AND MODELING \\ WHAT: Eighty-five researchers from 15 countries and districts met to synthesize the latest scientific findings in urban weather and climate research and explore new directions and international collaborations in urban meteorology research \\ WHEN: 12-I5 July 20II \\ Where: Beijing, China}

One fundamental aspect of predicting the future risks and defining mitigation strategies is to understand the weather and regional climate affected by cities. For this reason, dozens of researchers from many disciplines and nations attended the Urban Weather and Climate Workshop. ${ }^{1}$ Twenty-five students from Chinese universities and institutes also took part. The presentations by the workshop's participants span a wide range of topics, from the interaction between the urban climate and energy consumption in climatechange environments to the impact of urban areas on storms and local circulations, and from the impact of

\footnotetext{
${ }^{1}$ The workshop was cosponsored by the Commission of Urban Meteorology of the Chinese Meteorological Society (CMS) and by the Board on the Urban Environment of the American Meteorological Society (AMS). It was hosted by the Institute of Urban Meteorology (IUM) of the Chinese Meteorological Administration (CMA).
} 
urbanization on the hydrological cycle to air quality and weather prediction.

Two panel discussions focused on the major issues linked to model development and evaluation and observing systems. The presentations are available online at www.cms 1924.org/cum-wksp /index-English.html. This meeting summary provides a review of these major issues and recommendations, which are grouped into a number of themes.

MODELING. Improving our understanding of urban physical processes is key to improving knowledge in urban meteorology and hence to building better models for various applications. In the last decade the number of models capable of representing the surface-atmosphere exchange processes in and over urban areas has increased significantly. They have been included within weather and climate models, where they have been used to simulate the urban atmosphere for a variety of purposes. While many models share the same nucleus, their configurations and degrees of complexity vary widely, having arisen from the needs determined by various applications and the search for a compromise between the type of information simulated and the constraints, such as CPU time needed to perform the runs.

Urban canopy model development. Representing vegetation-related processes is critical within urban models. The early challenge of urban models was to represent the dynamic and thermodynamic effects of buildings on the urban boundary layer and impacts of small-scale heterogeneities on the spatially averaged turbulent fluxes and mean flow. This is usually done by using a class of models referred to as urban canopy models (UCMs). However, urban vegetation is often a major component of the urban surface. Urban vegetation is important because it plays several roles: it is a source of latent heat that modifies the urban energy and water vapor budget, it is a sink (dry deposition) and a source of pollutants [biogenic volatile organic compounds (VOCs)], it modifies the total drag and reduces the ventilation in the street canyon, and it produces shadows. The recent model-intercomparison study of Grimmond et al. (2011) revealed "urban vegetation" as one critical parameter that strongly influences UCM performance.

The standard approach to incorporating vegetation effects in urban areas in most UCMs is to treat vegetation separately from the urban surfaces using a "tile" scheme. Recently, some UCMs have integrated vegetation into the urban canyon, accounting for radiation interactions with the other canyon elements (e.g., walls and roads). A second international urban canopy model comparison would be useful to evaluate these and other new developments, including incorporation of different classes of vegetation to be represented. Other issues that need to be addressed include the difference between urban and rural vegetation due to additional stresses (e.g., pollution and heat) and how to account for irrigation in the estimate of soil moisture.

Other important sources of uncertainties in UCMs were identified. They include the following:

- Wall functions used to estimate the heat fluxes as a function of the difference between surface and air temperatures. A current area of research is to use a large-eddy simulation (LES) approach to improve their estimate.

- Anthropogenic heat. Simple building energy models (BEMs) have been integrated into UCMs and in coupled weather and climate models, but work is needed to validate them and to estimate other sources of anthropogenic heat (e.g., traffic).

- UCM input parameters. Improving UCM input parameters is important for model development and evaluation. In many cases, a lack of information on some parameters has resulted in the creation of free tuning parameters used to close the gap between model results and measurements. This approach can interfere with the assessment of model capability to reproduce the physics of the system. To avoid such interference, it is necessary to develop methods to link UCM input parameters with physical parameters of urban areas (e.g., linking urban roughness length to building height variability) and then obtain those parameters for urban areas. Dataset development, such as the National Urban Database with Access Portal Tool (NUDAPT; Ching et al. 2009), is an excellent step forward. The impact of errors in parameters that are used to characterize sites also needs to be assessed.

Urban precipitation and hydrology. The study of urban impacts on precipitation, a much-debated subject and yet critical for city water resources, needs a multifaceted approach. Investigating these impacts involves dynamics, thermodynamics, and hydrological processes, and also requires accurate aerosol and cloud models, but current research often focuses on only one process and still bears significant uncertainties.

Integrating urban hydrological cycles in coupled atmospheric models is paramount for predicting city flood events and for water-resource and management 
applications. Urban-specific hydrological processes are largely absent in current weather and climate models because they are significantly affected by infrastructures moving water across natural flow boundaries. An urbanized watershed model needs to take into account water, wastewater, and storm water imports and exports, which can lead to a net loss or gain to the system compared to the natural system.

Urban boundary layer and other model physics. Accurate simulation of atmospheric phenomena over urban areas also depends on other model physics. Boundary layer schemes are important for determining model skill in urban areas. In particular, when the horizontal spatial resolution is $1 \mathrm{~km}$ or less (the resolution often needed to resolve urban areas), the basic assumptions of the standard one-dimensional schemes no longer hold, and research is needed to develop new schemes for accounting for interactions between 3D urban-surface heterogeneity and the boundary layer at these resolutions. Moreover, the urban atmosphere cannot be separated from its rural counterpart, and there can be as much uncertainty in simulating rural areas as there is for urban areas. For example, the problems in simulating rural stable boundary layers can affect nocturnal urban heat island intensity or katabatic winds that can, eventually, penetrate the city. For coastal cities, a good determination of the marine boundary layer and the roughness length over the water impact sea breeze penetration in the city.

Model evaluation. Model evaluation is a critical step to gauging progress in modeling the urban atmosphere. More observational data are needed, in particular vertical profiles, to assess model capabilities to simulate the vertical structure and height of the urban boundary layer. Thermal remote sensing is another important source of information to validate UCMs' capability to simulate surface temperatures. Existing networks of surface stations are also valuable sources of information. The main problem is to determine the spatial representativity of such stations in order to perform meaningful comparisons with model outputs. In this regard, the use of computational fluid dynamics (CFD) microscale models, coupled with mesoscale models, has been recognized as a promising approach to resolve the impact of the urban spatial heterogeneities on point measurements. Techniques must be developed to optimize the coupling between mesoscale and microscale models, both in one-way (downscaling) and two-way (downscaling and upscaling) mode. The impact of measurement errors of both variables and parameters that are used to characterize sites needs to be assessed.

\section{NEW OBSERVING TECHNOLOGIES AND} ASSIMILATION APPROACHES. New technologies such as motes, lidars, sodars, and fiber optical temperature measurements provide the opportunity to obtain atmospheric variables in greater spatial detail both horizontally and, even more critically, vertically. In parallel with the development of new technologies, a wide range of new instrument platforms including unmanned aerial vehicles (UAVs) and small self-contained instruments such as motes, HOBOs, and TinyTags have become available. These offer new opportunities to answer some interesting questions. New technologies allow the potential for rich datasets to be created through data mining. For example, building temperature, cellphone-derived humidity, automobile-reported temperatures, and windshield wiper, brakes, and lights on/off status from onboard sensors that include location information are expected to become easily available in the near future. Such datasets might provide new insight into urban meteorology and its impact on human activities. Participants noted the need for measurements that relate to indoor and outdoor human activities, comfort, and quality of life. However, in all cases, it is critical that users of such data take care to ensure they understand what the data represent. This means that we must be careful with the siting of such instruments and collection of metadata so that there is a good understanding of what data have been collected, for what original purpose, and with what uncertainty.

In the case of both existing and new sources of urban observations we require new approaches for assimilating urban observations. Because of the presence of heterogeneities in urban areas, extreme care needs to be taken to ensure the spatial representativeness of urban measurements. As this is often not resolved ideally, because of logistical constraints, traditional data-assimilation techniques developed for rural areas are likely not appropriate for urban stations. However, the more pressing issue is the absence of equivalent local-scale measurements as used for rural areas.

Despite the new technologies, it looks as though there are some locations within cities where measurements will remain difficult to obtain. Notably, the vertical information from surface/canopy-layer sensors and the first gates of vertical profiling systems are likely to remain a challenge. In areas of tall buildings this information would be extremely useful as there 
are few observations. This gap is one where it is likely a synergy between modeling approaches, including numerical (CFD) and physical (wind tunnel) measurements, will be beneficial to providing new insight.

MODELING AND OBSERVATION INTEGRATION. Both measurements and modeling require a clear statement of the intended application so that the appropriate compromises between approaches to achieve the goal (e.g. practical constraints, costs, and permissions for siting), which are always required, are the correct ones. Discussions between researchers focused on measurements and modeling must be encouraged so that both groups are aware of limitations and what would provide complementary information. Using urban canopy-layer air temperature as an example, discussions could include where measurements of air temperature can realistically take place and what the implications of such measurement locations mean for model evaluation.

Modeling can also inform measurements. Models provide the ability to ask questions such as Where would be the best place to locate instruments? Where are places of little or large change in variables being observed? What areas will/will not be spatially representative? How can microscale measurements be used for mesoscale model evaluation? How does the spatial representativeness vary with wind direction? Given the respective shortcomings in observing and modeling complex urban meteorology, a better integration of the modeling and observation approaches is needed to make progress in our understanding and thus better parameterization with respect to applications.

END USERS' CONNECTION. Finally, the workshop participants noted that it is important to establish close collaborations with end users and define evaluation objectives and criteria that fit the purpose of model use. End users employ various modeling and observations techniques for tackling problems such as public health and risk assessment, city adaptation and mitigation to climate change, emergency response, urban water and energy use, etc. Connecting the traditional urban research community with the end user community is mutually beneficial for developing new or improved application tools.

ACKNOWLEDGMENTS. The International Workshop on Urban Weather and Climate: Observation and Modeling was supported by National Natural Science Foundation of China (41110304028) and the Ministry of Science and Technology of China (GYHY200906026).

\section{REFERENCES}

Ching, J., and Coauthors, 2009: National Urban Database and Access Portal Tool. Bull. Amer. Meteor. Soc., 90, 1157-1168.

Grimmond, C. S. B., and Coauthors, 2011: Initial results from Phase 2 of the international urban energy balance model comparison. Int. J. Climatol., 31, 244-272, doi:10.1002/joc.2227. 